\title{
Silica Sulfuric Acid: An Efficient Heterogeneous Catalyst for the One-Pot Synthesis of 1,4-Dihydropyridines under Mild and Solvent-Free Conditions
}

\author{
Bandita DATTA, M. Afzal PASHA* \\ Department of Studies in Chemistry, Central College Campus, Bangalore University, Bengaluru 560001, India
}

\begin{abstract}
A series of 1,4-dihydropyridines have been prepared by a one-pot condensation of aldehydes, ethyl acetoacetate, and ammonium acetate in the presence of a heterogeneous catalyst silica sulfuric acid at room temperature under solvent-free condition. This new protocol has the advantage of short reaction time and excellent yields, and is an environmentally benign route to the synthesis of 1,4-dihydropyridines.
\end{abstract}

Key words: aldehyde; ethyl acetoacetate; ammonium acetate; silica sulfuric acid; 1,4-dihydropyridine

CLC number: O643 Document code: A

Received 28 April 2011. Accepted 31 May 2011.

*Corresponding author. Tel: +91-80-22961337; Fax: +91-80-22961331; E-mail: m_af_pasha@ymail.com

English edition available online at Elsevier ScienceDirect (http://www.sciencedirect.com/science/journal/18722067).

In synthetic organic chemistry a one-pot synthesis has become a blue print to improve the efficiency of a reaction wherein a reactant is subjected to successive chemical reactions in one vessel [1]. The advantage of this strategy involves: i) use of commercially available starting materials; ii) avoiding a lengthy separation of the intermediates; iii) saving time and resources; iv) achieving increase in the chemical yield, and one such one-pot synthesis is of 1,4-dihydropyridines.

1,4-Dihydropyridine (DHP) scaffold has been shown to possess remarkable pharmacological activities [2]. 1,4-Dihydropyridines (DHPs) such as nifedifine, nitrendipine, and nimodipine, have been proved to be an important class of calcium-channel modulators $[3,4]$ and have been introduced as potential drugs for the treatment of congestive heart failure [5]. DHPs act as potent vasodilators, antihypertensives, bronchodilators, antiatherosclerotics, hepatoprotective, antitumor, antimutagenic, geroprotective, and antidiabetic agents [6]. They are also useful as cognition enhancers, neuroprotectants, and platelet antiaggregatory agents [7-9]. DHP esters serve as biomimetic reducing agents such as NADPH and NADH models also [10,11].

In 1881, Arthur Rudolf Hantzsch was the first to report the synthesis of DHPs by a one-pot reaction of an aldehyde, a $\beta$-ketoester, and aqueous ammonium hydroxide in ethanol [12]. Since then a series of procedures have been developed for the synthesis of DHPs. The reported procedures involve the use of reagents and catalysts such as Montmorillonite $\mathrm{K} 10$ [13], TBAB [14], $\mathrm{HClO}_{4} \cdot \mathrm{SiO}_{2}$ [15], $\mathrm{I}_{2}$ [16], silica gel/ $\mathrm{NaHSO}_{4}$ [17], $\mathrm{AlCl}_{3} \cdot 6 \mathrm{H}_{2} \mathrm{O}$ [18], 2,4,6-trichloro[1,3,5]- triazines (TCT, cyanuric chloride) [19], ionic liquid/3,4,5-trifluorobenzeneboronic acid [20], sulfonic acid [21], and fermenting bakers' yeast [22] under various conditions such as ultrasound [23], microwave irradiation [24], and high temperature in refluxing solvent [25]. Moreover, procedures involving use of $\beta$-enaminones [26] as substrates have also been reported for the synthesis of DHPs. Recently, $\mathrm{CeCl}_{3} \cdot 7 \mathrm{H}_{2} \mathrm{O}$ [27], $\mathrm{PW} / \mathrm{SiO}_{2}$ [28], and $\mathrm{PPh}_{3}$ [29] have been employed for this condensation reaction.

In the 19th century considering economic and environmental aspects, heterogeneous catalysts have gained a lot of importance [30-32], and silica sulfuric acid has been widely used as a stable and an efficient heterogeneous catalyst. Silica sulfuric acid produces little waste with excellent activity and selectivity. Silica sulfuric acid can be prepared facilely by treating chlorosulfonic acid with silica gel $[33,34]$ and is a better reagent when compared to a solely homogeneous acid such as chlorosulfonic acid or sulfuric acid (Scheme 1).

Herein, we report an efficient and convenient procedure for the synthesis of DHPs from ethyl acetoacetate, aldehyde, and ammonium acetate using silica sulfuric acid as catalyst (Scheme 2). Once the reaction goes to completion, the catalyst can be filtered, washed with warm ethanol, and reused without decrease in activity for four runs.

\section{Experimental}

All reagents were commercial available and used without further purification. The products were characterized by ${ }^{1} \mathrm{H}$ 


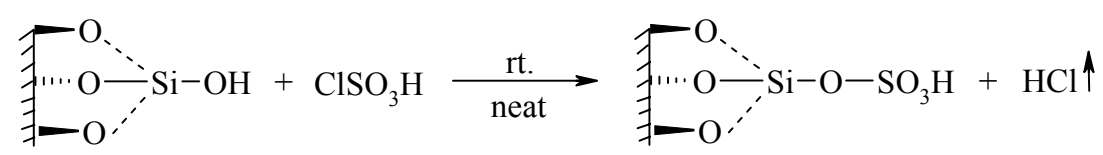

Scheme 1. Preparation of silica sulfuric acid.

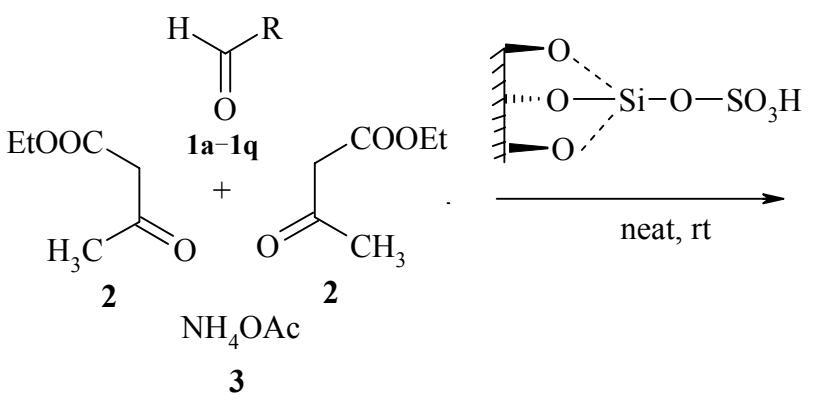<smiles>[R]C1C(C(=O)OCC)=C(C)NC(C)=C1C(=O)OCC</smiles>

Scheme 2. Synthesis of DHPs from ethyl acetoacetate, aldehyde, and ammonium acetate.

NMR and mass spectral analyses. The melting points were measured on a Raaga (Chennai) melting point apparatus. NMR spectra of the products were recorded on Bruker AMX 400-MHz spectrophotometer. LC-MS and GC-MS were performed on an Agilent Technologies 1200 series instrument and on a Shimadzu GC-MS QP 5050A instrument, respectively.

In a general experimental procedure for the synthesis of DHPs, a mixture of ethyl acetoacetate $(10 \mathrm{mmol})$, aldehydes $(5 \mathrm{mmol})$, ammonium acetate $(5 \mathrm{mmol})$, and silica sulfuric acid $\left(0.1 \mathrm{~g}, 0.26 \mathrm{mmol}\right.$ of $\left.\mathrm{H}^{+}\right)$[27] were mixed in a round-bottom flask and stirred at room temperature (for a stipulated time as indicated in Table 1) under solvent-free condition. After completion of the reaction (detected by TLC), ethyl acetate $(5 \mathrm{ml})$ was added to the reaction mixture and the catalyst was filtered, washed with warm ethanol for reuse. The filtrate was then washed with water $(5 \mathrm{ml})$ followed by brine solution $(10 \mathrm{ml})$ and dried over $\mathrm{MgSO}_{4}$. The solution was concentrated in vacuum to afford the crude product. Then, the crude product was further purified by silica gel column chromatography. Yields of all the products prepared by this procedure are presented in Table 1 .

\section{Results and discussion}

In continuation of our ongoing studies towards the development of new environmentally friendly protocols for the synthesis of biologically active molecules through solid-supported catalyst in a one-pot synthesis [35-40], we report a simple and efficient procedure for the synthesis of 1,4-dihydropyridines using non-toxic, environmental friendly, and reusable silica sulfuric acid as a catalyst herein.
In an initial endeavor, ethyl acetoacetate $(10 \mathrm{mmol})$ was treated with benzaldehyde $(5 \mathrm{mmol})$ and ammonium acetate $(5 \mathrm{mmol})$ in methanol and stirred for $24 \mathrm{~h}$ to get the desired product in $10 \%$ yield. To optimize the reaction conditions, we added silica sulfuric acid to the reaction mixture and allowed to stir for $30 \mathrm{~min}$, which produced $70 \%-80 \%$ of the product. In order to further increase the yield, we treated ethyl acetoacetate $(10 \mathrm{mmol})$ with benzaldehyde $(5 \mathrm{mmol})$ and ammonium acetate $(5 \mathrm{mmol})$ in the presence of silica sulfuric acid under solvent-free condition to get the product in $96 \%$ yield. It was also found that, this high yield was obtained with $100 \mathrm{mg}$ of the catalyst and use of excess of the catalyst did not remarkably increase the yield. With the optimal conditions on hand, further investigations were carried out to expand the scope of use of other aldehydes and the results are summarized in Table 1.

A series of aromatic aldehydes and formaldehyde have been investigated, and it can be seen from Table 1 that, aromatic aldehydes bearing both electron-donating and electron-withdrawing groups have no obvious effect on the yields and reaction time under the above optimal conditions. We also examined the said reaction with heteroaromatic aldehydes like furfural (1j) to get the corresponding product $(\mathbf{4 j})$ in high yield.

Finally, under optimized conditions the recycling of the catalyst for the reaction was carried out. As silica sulfuric acid is a heterogeneous catalyst, it was separated by simple filtration and reused after washing with ethyl acetate and warm ethanol (Fig. 1). In every case, $>90 \%$ of silica sulfuric acid was recovered. The results showed that the catalyst could be used 5 times without major loss of activity.

On the basis of our experimental results and together with literature reports [22], we have proposed a plausible mecha- 
Table 1 Synthesis of 1,4-dihydropyridines from ethyl acetoacetate, aldehyde, and ammonium acetate

\begin{tabular}{lcccc}
\hline Product $^{\mathrm{a}}$ & $\mathrm{R}$ & Time $(\mathrm{min})$ & Yield $^{\mathrm{b}}(\%)$ & Melting point $^{\mathrm{c}}\left({ }^{\circ} \mathrm{C}\right)$ \\
\hline $\mathbf{4 a}$ & $\mathrm{H}$ & 15 & 97 & $182(183-185)$ \\
$\mathbf{4 b}$ & $\mathrm{C}_{6} \mathrm{H}_{5}$ & 20 & 96 & $155(155-157)$ \\
$\mathbf{4 c}$ & $4-\mathrm{CH}_{3} \mathrm{OC}_{6} \mathrm{H}_{4}$ & 30 & 95 & $156(158-160)$ \\
$\mathbf{4 d}$ & $3-\mathrm{CH}_{3} \mathrm{O}, 4-\mathrm{HOC}_{6} \mathrm{H}_{3}$ & 27 & 91 & $163(163-164)$ \\
$\mathbf{4 e}$ & $3,4-\left(\mathrm{CH}_{3} \mathrm{O}\right)_{2} \mathrm{C}_{6} \mathrm{H}_{3}$ & 90 & $161(163-164)$ \\
$\mathbf{4 f}$ & $3,4,5-\left(\mathrm{CH}_{3} \mathrm{O}\right)_{3} \mathrm{C}_{6} \mathrm{H}_{2}$ & 45 & 93 & $140(140-142)$ \\
$\mathbf{4 g}$ & $4-\mathrm{NO}_{2} \mathrm{C}_{6} \mathrm{H}_{4}$ & 92 & $128(129-130)$ \\
$\mathbf{4 h}$ & $3-\mathrm{NO}_{2} \mathrm{C}_{6} \mathrm{H}_{4}$ & 45 & 97 & $160(162-164)$ \\
$\mathbf{4 i}$ & $2-\mathrm{NO}_{2} \mathrm{C}_{6} \mathrm{H}_{4}$ & 40 & 91 & $170(171)$ \\
$\mathbf{4 j}$ & $2-\mathrm{C}_{4} \mathrm{H}_{3} \mathrm{O}$ & 95 & $163(164)$ \\
$\mathbf{4 k}$ & $4-\mathrm{HOC}_{6} \mathrm{H}_{4}$ & 37 & 95 & $227(227-28)$ \\
$\mathbf{4 I}$ & $2-\mathrm{HOC}_{6} \mathrm{H}_{4}$ & 35 & 91 & $121(122)$ \\
$\mathbf{4 m}$ & $4-\mathrm{ClC}_{6} \mathrm{H}_{4}$ & 25 & 96 & $143(145-146)$ \\
$\mathbf{4 n}$ & $3-\mathrm{ClC}_{6} \mathrm{H}_{4}$ & 30 & 92 & $141(142)$ \\
$\mathbf{4 o}$ & $2-\mathrm{ClC}_{6} \mathrm{H}_{4}$ & 27 & 93 & $216(216-218)$ \\
$\mathbf{4 p}$ & $4-\left(\mathrm{CH}_{3}\right)_{2} \mathrm{NC}_{6} \mathrm{H}_{4}$ & 35 & 90 & $201(203)$ \\
$\mathbf{4 q}$ & $3,4-\left(\mathrm{OCH}_{2} \mathrm{O}\right) \mathrm{C}_{6} \mathrm{H}_{3}$ & 30 & 94 & $163(164)$ \\
\hline
\end{tabular}

${ }^{a}$ All the products are known and $\mathbf{4 b}, \mathbf{4 c}$, and $\mathbf{4 g}$ are characterized by ${ }^{1} \mathrm{H}$ NMR spectral analysis. Mass spectral data and IR spectra of all the products $(\mathbf{4 a - 4 q )}$ matched with the reported data.

${ }^{\mathrm{b}}$ Isolated yields.

${ }^{c}$ The numbers in brackets are melting points of the samples prepared by the reported method [17].

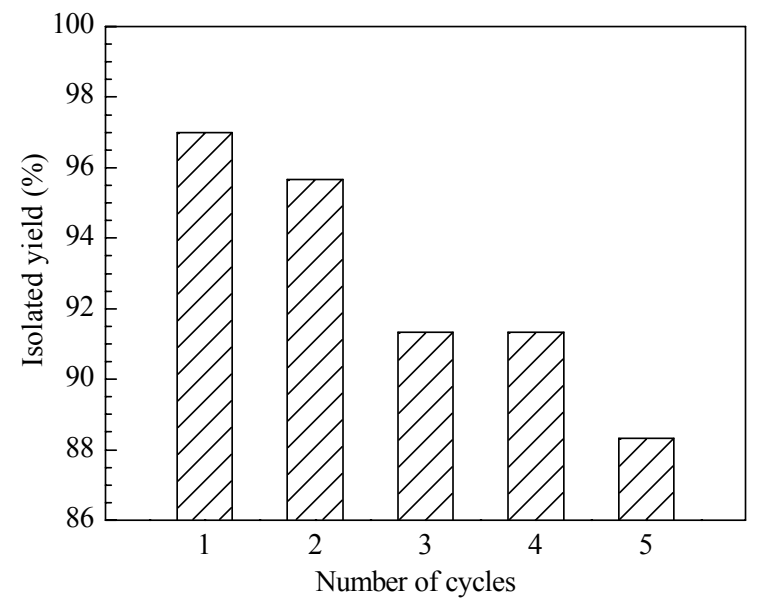

Fig. 1. Repeated use of silica sulfuric acid for the synthesis of 1,4-dihydropyridines under solvent-free condition at $25^{\circ} \mathrm{C}$.

nism for the formation of 1,4-dihydropyridines on silica sulfuric acid (Scheme 3). The reaction is supposed to proceed via two steps. The first step involves silica sulfuric acid-catalyzed formation of Knoevenagel product I from 1 equivalent of ethyl acetoacetate and aldehyde. The next step comprises of formation of $\beta$-enaminoesters II from the second equivalent of ethyl acetoacetate and ammonia (generated 'in situ' from ammonium acetate). Condensation of fragments I and II may give intermediate III, which in a subsequent step gets converted to 1,4-dihydropyridine by cyclization followed by dehydration.

\section{Conclusions}

A simple and efficient methodology for a one-pot synthesis of 1,4-dihydropyridines from ethyl acetoacetate, aldehyde, and ammonium acetate in the presence of heterogeneous catalyst silica sulfuric acid has been developed. This new protocol has advantages including: (i) the use of small amount $(0.1 \mathrm{~g})$ of inexpensive, easy to handle, and reusable catalyst; (ii) short reaction times (15-45 min); and (iii) high yields (90\%-97\%). We believe that use of a heterogeneous catalyst and a solvent-free reaction set up in this protocol is environment-friendly and can be applied for large-scale operations.

\section{References}

1 Shaabani A, Samadi S, Rahmati A. Synth Commun, 2007, 37: 491

2 Stout D M, Meyers A I. Chem Rev, 1982, 82: 223

3 Bossert F, Meyer H, Wehinger E. Angew Chem, Int Ed, 1981, 9: 762

4 Nakayama H, Kasoaka Y. Heterocycles, 1996, 42: 901

5 Sunkel C E, de Casa-Juana M F, Santos L, Garcia A G, Artalejo C R, Villarroya M, Gonzalez-Morales M A, Lopez M G, Cillero J. J Med Chem, 1992, 35: 2407

6 Vo D, Matome W C, Ramesh M, Iqbal N, Wolowyk M W, Howlett S E, Knaus E E. J Med Chem, 1995, 38: 2851

7 Janis R A, Triggle D J. J Med Chem, 1983, 25: 775

8 Bocker R H, Guengerich F P. J Med Chem, 1986, 28: 1596 
<smiles>[R]C=C(C(=O)OCC)C(=O)OCC(=O)OCC</smiles>

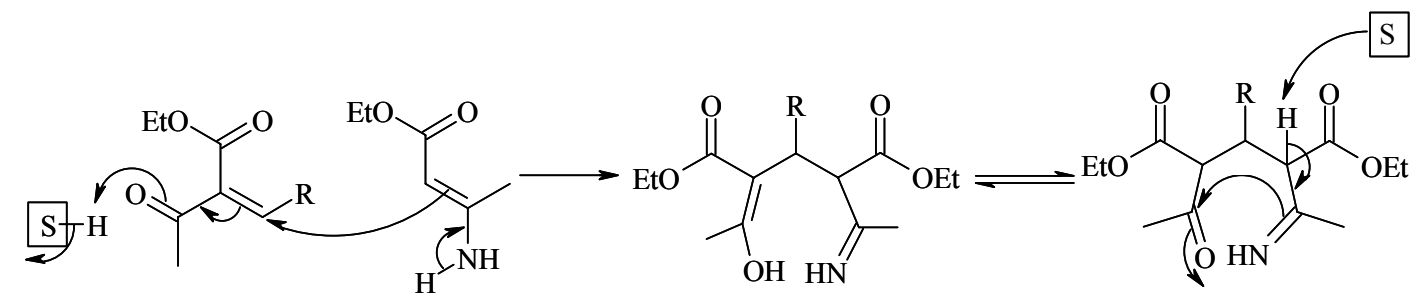<smiles>[R]C1C(C(=O)OCC)=C(C)NC(C)(O)C1C(=O)OCC</smiles><smiles>[R]C1C(C(=O)OCC)=C(C)NC(C)=C1C(=O)OCC</smiles>

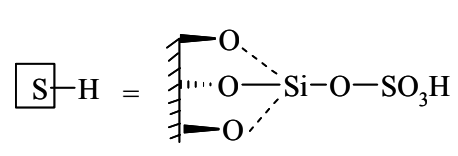

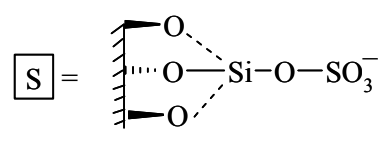

Scheme 3. A plausible mechanism for the formation of 1,4-dihydropyridines.

9 Sausins A, Duburs G. Heterocycles, 1988, 27: 269

10 Cooper K, Fray M J, Parry M J, Richardson K, Steele J. J Med Chem, 1992, 35: 3115

11 Lavilla R. J Chem Soc, Perkin Trans I, 2002, 1141

12 Love B, Sander K M. J Org Chem, 1965, 30: 1914

13 Zonouz A M, Hosseini S B. Synth Commun, 2008, 38: 290

14 Salehi H, Guo Q X. Synth Commun, 2004, 34: 4349

15 Maheswara M, Siddaiah V, Rao Y K, Tzeng Y M, Sridhar C. $J$ Mol Catal A, 2006, 260: 179

16 Akbari J D, Tala S D, Dhaduk M F, Joshi H S. ARKIVOC, 2008, (12): 126

17 Chari M A, Syamasundar K. Catal Commun, 2005, 6: 624

18 Sharma S D, Hazarika P, Konwar D. Catal Commun, 2008, 9: 709

19 Sharma G V M, Reddy K L, Lakshmi P S, Krishna P R. Synthesis, 2006: 55

20 Sridhar R, Perumal P T. Tetrahedron, 2005, 61: 2465

21 Gupta R, Gupta R, Paul S, Loupy A. Synthesis, 2007, 18: 2835

22 Lee J H. Tetrahedron Lett, 2005, 46: 7329
23 Wang S X, Li Z Y, Zhang J C, Li J T. Ultrasonics Sonochem, 2008, 15: 677

24 Yadav J S, Reddy B V S, Reddy P T. Synth Commun, 2001, 31: 425

25 Kawase M, Shah A, Gaveriya H, Motohashi N, Sakagami H, Varga A, Molnar J. Bioorg Med Chem, 2002, 10: 1051

26 Yadav J S, Reddy B V S, Basak A K, Narsaiah A V. Green Chem, 2003, 5: 60

27 Sabitha G, Arundhathi K, Sudhakar K, Sastry B S, Yadav J S. Synth Commun, 2009, 39: 2843

28 Rafiee E, Evani S, Rashidzadeh S, Joshaghani M. Inorg Chim Acta, 2009, 362: 3555

29 Debache A, Ghalem W, Boulcina R, Belfaitah A, Rhouati S, Carboni B. Tetrahedron Lett, 2009, 50: 5248

30 Samajdar S, Becker F F, Naik B K. Tetrahedron Lett, 2000, 41: 8017

31 Bahulayan D, Narayan G, Sreekumar V, Lalithambika M. Synth Commun, 2002, 32: 3565

32 Srinivas K V N S, Das B. Synlett, 2004, 1715

33 Mirjalili B F, Zolfigol M A, Bamoniri A. Molecules, 2002, 7: 
751

34 Salehi P, Dabiri M, Zolfigol M A, Fard M A B. J Braz Chem Soc, 2004, 15: 773

35 Pasha M A, Jayashankara V P. Bioorg Med Chem Lett, 2007, 17: 621

36 Pasha M A, Jayashankara V P, Ramachandrawswamy N. Synth Commun, 2007, 37: 1551
37 Pasha M A, Jayashankara V P. Indian J Chem, 2007, 46B: 1025

38 Pasha M A, Jayashankara V P. Synth Commun, 2006, 36: 1787

39 Rama K, Pasha M A. Ultrasonics Sonochem, 2005, 12: 437

40 Nanjundaswamy H M, Pasha M A. Synth Commun, 2007, 37: 3417 